\title{
Selecting Rare Books for Physical Conservation: Guidelines for Decision Making
}

\author{
Lisa B. Williams
}

When funds are limited, librarians and curators responsible for selecting rare books for conservation treatment must base their decisions not only upon physical condition, but also upon the "value" assigned to each physically deteriorated book. This article discusses the rationale for, and possible uses of, guidelines designed to facilitate conservation decisions by systematically evaluating and weighing such factors as monetary, intellectual, and aesthetic value, projected use, and usability.

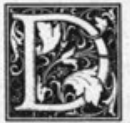

eciding which books in a library collection should receive conservation treatment is rarely simple. Particularly in a special collections department or rare book library, conservation is a complex process of analysis, evaluation, and resolution, as the physical requirements of each volume must be weighed against its intellectual and intrinsic value, the availability of financial resources, and the priorities of the institution. Although any consideration of book conservation by librarians generally focuses on the technical aspects of diagnosis and treatment, another level of decision making is usually required: in a time when severely curtailed budgets are the norm, librarians, curators, and conservators are forced to select for treatment only a few of the many potential candidates in a collection.

The failure to consider this essential administrative aspect of the book conservation process is clearly apparent in the literature. It is not news that library materials are physically deteriorating and that libraries must accept the responsibility for their preservation. The problem of unstable and brittle books has become a major topic in library literature. Book conserva- tion has emerged as an independent and growing subfield of librarianship with a literature of its own. But, while technical problems have received considerable attention, the role of the librarian or administrator in conservation has been all but overlooked.

\section{ROLES IN CONSERVATION}

It is widely acknowledged that the librarian has such a role. Several writers during the last few decades have noted the problem of curatorial involvement; typically, however, discussion has been general or theoretical and offers little practical guidance. This statement is typical:

Until such time as effective and economical techniques for mass treatment become available, librarians will need to be highly selective in the materials they preserve and will have to make decisions with respect to the best and most appropriate means of preserving them. Priority should be given to materials that are unique or believed to be not commonly held and to materials of local significance. ${ }^{1}$

Established institutional conservation programs are dependent upon librarians for the selection of items to be preserved, but the process of selection is rarely spelled out. ${ }^{2}$ At least two libraries with ac-

Lisa B. Williams is director of major gifts and research, Whittier College, Whittier, California 90608. She was a Council on Library Resources Fellow in 1982-83 at the University of Chicago, where this study was conducted.

- 1985 Lisa B. Williams. 
tive programs are explicit in ascribing overall responsibility to the librarian rather than to the conservator. At Yale University consideration has been given to the factors that influence conservation decisions. The conclusion is:

Decisions should be made by persons most familiar with the subject or language of the book being processed, since they can best assess the importance of the title to the collections. The preservation officer's knowledge of paper and binding and the relative costs and benefits of various options is important, but the final decision should rest with the subject specialist or collection development officer. ${ }^{3}$

\section{Similarly, at Southern Illinois University:}

Decisions to treat individual items or whole collections are made jointly by the Conservation Librarian and the divisional librarian responsible for the material. Selection of the most suitable treatment is a decision initiated by the divisional librarian (who is in the best position to know the item's value and intended use) on the advice of the Conservation Librarian, who is responsible for choosing the best combination of methods and materials. ${ }^{4}$

At Yale and Southern Illinois, however, the librarians responsible for such decisions do not have any mechanism for systematically evaluating the "value and intended use" of a large and diverse body of physically "needy" books.

George Cunha has clearly articulated the role of the librarian in conservation decisions. In "The Tripartite Concept of Conservation," He describes conservation as a joint responsibility of the scientist, the conservator, and the custodian, i.e., the librarian/administrator, and defines the latter's role as "decision making based on all the considerations involved in addition to the conservation factors." Recommending simple and effective ways for libraries to identify and address their conservation problems, Cunha stresses the need for at least one library staff member competent to judge not only the physical requirements of a book but also its value to the collection, and identifies some of the factors upon which such judgments might be based:

- Relation of each damaged book to the entire collection

- Research or historical importance of the volume
- Importance based on frequency of use

- Permanent versus temporary importance of each ${ }^{6}$

These are issues that are addressed regularly by museum professionals who, having traditionally exhibited greater sensitivity to the physical condition of their collections than librarians, have assigned the curator/administrator a formal role in conservation activities. Both regular collection surveys and instruments for systematically reporting condition and treatment have long been standard in museums. The generalized emphasis upon "administrative conservation" in museums includes curatorial responsibilities such as verification of the condition of items and justification of the funds necessary to carry out any required action. ${ }^{7}$ Accordingly, museums rely heavily upon formal documentation of condition, treatment, use, and other pertinent information about each object.

In practice, these convictions may translate into elaborate prescriptive systems for evaluating and describing items with regard to both conservational needs and, to a lesser extent, curatorial value. Museum reporting forms allow both systematic assessment according to curatorial standards and extremely detailed physical description and analysis. Both the conservator and curator typically set rankings for each item under consideration. Some institutions use a more complex standardized system, and space for additional curatorial comment generally is provided.

Museum models are suitable for "special" library collections of rare books or other unusual materials. These collections differ from general library collections in a number of ways:

1. Materials are unique and therefore not amenable to normal assumptions about condition or importance.

2. Collections are more likely to be developed and maintained to conform to some abstract concept of excellence or completeness rather than to respond to the immediate needs of any constituency.

3 . Frequency of use cannot be assumed to be a reliable indicator of the value of a book to the collection.

4. Relatively small size and relatively 
high costs per item may permit an attentiveness to detail not possible in the large collection.

These differences will be reflected in the administration of a conservation program for a special collection, whether in an independent library or as part of a larger institution. An effective decision-making strategy for the physical conservation of special collections is likely to resemble the descriptive, item-by-item survey typical of museum conservation; highly generalized mass approaches that might be ideal for a large general library are not appropriate. ${ }^{10}$

\section{THE STUDY}

The study was undertaken with the cooperation of the Department of Special Collections, Regenstein Library, the University of Chicago. Guidelines were designed to enable deteriorating rare books to be more systematically selected for treatment. ${ }^{11}$ They were then refined through use, with a group of test volumes drawn from the rare book collection of the John Crerar Library (see Appendix A). Because the guidelines are intended for use in a collection-wide survey and must apply equally to a variety of physical problems likely to occur in a rare book library, forty-three exemplary volumes were selected from the following categories:

I. Contemporary bindings
A. Sixteenth century
B. Seventeenth century
C. Eighteenth century
D. Nineteenth century

II. Rebindings
A. Nineteenth century
B. Buckram

III. Previous repairs
A. Rebacking
B. Paper repair

IV. Special problems
A. Brittle paper
B. Flat items (e.g., maps, unbound plates)
C. Pamphlets and paper covers

Each volume was assigned a numerical value scale for each of five criteria-one (least valuable) through ten (most valuable). An overall priority ranking was obtained for each volume by totaling the five scores. Volumes could also be compared on the basis of any single criteria.
Criteria were identified and refined through discussions with working conservators and librarians who regularly make conservation decisions. The five criteria are

1. Monetary value. This should reflect the price a library might expect to pay to acquire the particular title or edition. Because numerical scores are used, no dollar values are necessary. Only relative value is assessed.

2. Intellectual value. Both the usefulness of the work to scholars and the historical significance of the work are considered.

3. Aesthetic value. This should reflect the significance, attractiveness, and integrity of the book as an artifact of bibliographical history.

4. Projected use. Here judgment should focus on the projected use of the volume by students and scholars, the research value of the work, and the availability of reprints or other editions.

5. Usability. This should indicate whether the volume in its present condition could be used without physical damage to the book. Because a book is held in a library chiefly, if not exclusively, for this purpose, usability is an extremely important factor. Therefore, this category is scored simply yes or no: either one (yes, the volume can be used) or ten (no, the volume cannot be used.) This exceptional scoring technique effectively raises the overall priority ranking of any item judged not usable. See table 1 for an example of ranking for a sample volume.

After the guidelines were evaluated and revised, six experts were called upon to test their usefulness. The experts came from a variety of backgrounds and included conservators, librarians, and

TABLE 1

RANKING FOR SAMPLE VOLUME: AN EXAMPLE*

\begin{tabular}{lc}
\hline \hline \multicolumn{1}{c}{ Criteria } & Ranking \\
\hline Monetary Value & 6 \\
Intellectual Value & 5 \\
Aesthetic Value & 4 \\
Projected Use & 2 \\
Usability & 1 \\
\cline { 2 - 2 } & 18 \\
\hline
\end{tabular}

*Guy de Chauliac. Cyrurgia. Venice: 1519. 
scholars. Their viewpoints and experience were diverse. Each judged the sample volumes in accordance with the experimental model and discussed his or her evaluation of a single preselected volume (the same volume was used for each judge), noting any questions or impressions concerning the experimental model or the criteria by which it was formulated.

In general, the results of the test were encouraging (see Appendix B). The judges used the assessment criteria without difficulty. None of the criteria was viewed as irrelevant or inappropriate. One judge assigned scores of only one or two in the "projected use" category but because all other judges used a broad range of scores for this category, it remained valid for our purposes. Two judges suggested that they were using criteria not specifically included in the guidelines: one, a specialist in the history of the book, judged a volume's significance from that perspective; the other judged a volume's pertinence to current and ongoing research in his particular institution. This variability was not considered sufficiently unusual to warrant adding new criteria. Another judge noted that she resisted the temptation to rank volumes in her own field of research as more useful than those in other fields.

Most of the judges expressed reservations about making quick judgments, particularly about monetary value and projected use. This is a legitimate concern, but the issue must be viewed in perspective. In any real situation, a decision to conserve a book no doubt will require quick judgment, based on apparent or available information. Only in unusual circumstances would a book be thoroughly researched before making a decision-for example, a very rare, significant, or expensive volume, or one requiring extensive, costly treatment. The judges may have been reacting to the experimental environment in which fortythree volumes were evaluated as discrete items, not as part of regular collections. Nonetheless, the resulting judgmental errors are not likely to skew the results of the survey substantially, since only relative judgments were required. It is worth not- ing that all judges were able to make most of the necessary evaluations in spite of expressed discomfort about quick judgments.

While each judge's scores for the fortythree sample volumes resulted in a usable priority ranking, the rankings varied widely among the judges. ${ }^{12}$ Some volumes were ranked similarly by most of the judges: volume number 31, for example, was ranked $19,13,13,13,13$, and 8 , and number 19 was ranked 37, 41, 35, 41, 30, and 33 . Other rankings, however, were quite dissimilar: for example, number 15 was ranked 17, 4, 30, 22, 41, 25. The magnitude, if not the fact, of this variation was unexpected. It is clear, even from the very small number of judges included in this test, that the individual knowledge, expertise, and perspective of a judge has considerable influence upon his or her judgments. $^{13}$

\section{POSSIBLE USE AND FUTURE STUDY}

To be effective as an administrative tool, the decision-making guidelines used in this study will need to be augmented by other nonjudgmental criteria. First, the physical condition of the volume must be recorded. I did not include this information because the true physical condition of a book often is not apparent to the untrained eye and, within limits, diagnosis, unlike priority, is likely to be unaffected by the point of view of the individual judge. Second, certain objective factors, such as date and place of publication and previous treatments, which are useful in isolating individual volumes for treatment, should be recorded.

Thus, a decision-making model designed for actual use might include several kinds of variables: the five subjective criteria used here and the total value score, objective criteria, and physical requirements. Decisions might be made on the basis of any combination of these variables, in order to take advantage of available conservational resources or to plan long-range staffing or work patterns. For example, a library might wish to identify the volumes with the highest total value scores that require recasing and deacidifi- 
cation, or the pre-nineteenth century volumes with the highest monetary value that require leather bindings. Clearly, a statistical software package would be useful in recording and manipulating these data.

While this study was designed with a collection-wide survey in mind, it should be useful in other situations as well. Traditionally, conservation decisions are made as volumes come to the attention of library staff. Such volumes could be evaluated routinely according to the guidelines. Books identified and scrutinized for other reasons, such as for exhibits, might be similarly evaluated. Such situational analysis is not, of course, an adequate substitute for a comprehensive survey, and a very strong argument can be made for regular, periodic evaluations of all holdings; nevertheless, consistent, systematic analysis of even a small and visible portion of the collection should make the decisionmaking process more routine.

As noted above, value judgments varied considerably among the six test judges. The ramifications of this variation for any practical use are obvious. One apparent solution is to limit evaluation on the subjective criteria to a single individual, probably a department head or chief librarian. Another possibility for a library that wishes to use the guidelines but cannot devote a large block of executive time to them is to define, as precisely as possible, the system of values operative in that institution; then, within this system, to accept the evaluations of several judges as equally valid, regardless of variations. On the basis of the work done in this study, it is unclear whether outlining the operative value system would significantly reduce the variation in individual judgments.

A preliminary study such as this may raise more questions than it answers. The demands and constraints of using these or any guidelines in a real situation can only be imagined or inferred from the results. Nevertheless, the approach described here does result in a workable, if not infallible, priority ranking of a diverse group of books with diverse physical problems. It is clear that some systematic means of deciding which books to conserve is necessary, and in a special collection, where every volume is assumed to be valuable as an object and the relative value of various volumes cannot be measured by use or currency, it is clear that mass approaches are unworkable. By isolating the criteria relevant to conservation decisions, analyzing the meaning and relativity of "value," and viewing each volume from a variety of perspectives, the librarian may be able to formalize heretofore ad hoc, intuitive decisions. It is, after all, the responsibility of the librarian not only to decide which books to treat, but to develop consistent, rational reasons for those decisions.

\section{REFERENCES AND NOTES}

1. James W. Henderson and Robert G. Krupp, "The Librarian as Conservator," in Howard W. Winger and Richard Daniel Smith, eds., Deterioration and Preservation of Library Materials (Chicago: Univ. of Chicago Pr., 1970), p.184. Other examples of theoretically useful but practically limited articles are W. G. Constable's "Curators and Conservation," in John P. Baker and Marguerite C. Soroka, eds., Library Conservation: Preservation in Perspective (Stroudsburg, Pa.: Dowden, Hutchinson \& Ross, 1978), p.154-58; and Robert Organ's "Organization and Management of Conservation Programs," in Robert C. Morrison, George M. Cunha, and Norman P. Tucker, eds., Conservation Administration (North Andover, Mass.: New England Document Preservation Center, 1975), p.213-85.

2. See, for example, the Association of Research Libraries, Office of Management Studies SPEC Kit 66, Planning for Preservation (July-Aug., 1980).

3. David Boardway, et al., Preservation: Your Responsibility (New Haven, Conn.: Yale University Library, 1982), p.22.

4. Planning for Preservation, p.69.

5. George M. Cunha, "The Tripartite Concept of Conservation," in Morrison, Cunha, and Tucker, Conservation Administration, p.46.

6. Cunha, What an Institution Can Do to Survey its Conservation Needs (New York: Resources and Tech- 
nical Services Section, New York Library Association, 1979), p.7.

7. Richard D. Buck, "On Conservation," Museum News 52:15 (1978).

8. Harold Barker, "Documentation of Conservation in Museums: The Quest for a Solution," ICOM Committee on Conservation Report, April 1, 1978 (Zagreb: 1978), p.1. Additional information on documentation and related topics may be found elsewhere in this report; in the previous ICOM conservation report (Madrid: 1972); and in Sharon Timmons, ed., Preservation and Conservation: Principles and Practices (Washington, D.C.: Preservation Press, 1976), as well as throughout the museum literature.

9. Numerous forms are collected in Written Documentation (Philadelphia: American Institute for Conservation of Historic and Artistic Works, 1981), the report of the ninth annual meeting of the American Institute for Conservation. Some libraries, notably the Newberry, use similar forms, but rarely are these as detailed or as alert to nonphysical factors.

10. Christopher Tomer's "Identification, Evaluation, and Selection of Books for Preservation," (Collection Management 3:45-54 (1979) is an important step toward systematizing conservation decisions for books in general libraries. Tomer relates the physical condition of books to date of publication (primarily nineteenth and twentieth centuries) and frequency of circulation, and suggests that conservation decisions can be generalized on the basis of these criteria. But this very generality makes Tomer's approach inappropriate for special collections.

11. No attempt was made to make the decision-making process objective. It was recognized from the outset that the evaluation of rare books is a highly subjective process dependent upon the knowledge and interest of the individual judge as well as the values and priorities of any single library or department. Consistent and rational decisions are the goal.

12. The range of scores was as follows: judge 1, 5-28; judge 2, 8-45; judge $3,7-37$; judge 4, 10-25; judge 5, 13-39; judge 6, 9-48. See Appendix B for priority rankings.

13. Interestingly, judges with apparently similar backgrounds and perspectives exhibited no greater uniformity of judgment than those with dissimilar backgrounds.

\section{APPENDIX A: SAMPLE VOLUMES}

1. Cellarius, Andreas. Planisphaerium Braheum. . . . Amsterdam: 1661.

2. Remmelin, Johann. Catoptrum Microcosmicum. Frankfurt-am-Main: 1660.

3. Zippel, Hermann. Ausländische Kulturpflanzen. Braunschweig: 1903.

4. (Sanders, Edgar, comp.) (Clippings on horticultural subjects.) (Chicago: ca. 1900.)

5. Kundmann, Johann Christian. Rariora Naturae et Artis Item in re Medica. Breslau: 1737.

6. Schück, Albert. Die Stabkarten. . . . Hamburg: 1902.

7. Schmettering. Lepidoptera.

8. Guy de Chauliac. Cyrurgia. Venice: 1519.

9. Tagault, Jean. Ambiani Vimaci. . . . Paris: 1543.

10. Lancisi, Giovanni Maria. De Subitaeis Mortibus. Venice: 1708.

11. Mead, Richard. Opera Medica. Naples: 1779.

12. Sowerby, James. British Mineralogy, V.II. London: 1809.

13. Colles, Abraham. Practical Observations on the Venereal Disease. . . . Philadelphia: 1837

14. Woodall, John. Methodos. . . . London: 1639.

15. James, William. The Principles of Psychology, V.II. New York: 1890.

16. Nederlanshe Reizen, V.II. Amsterdam: 1784.

17. Donati, Marcello. De Medica Historia Mirabili. . . . Venice: 1597.

18. Cuvier, Georges. The Animal Kingdom, V.IV. London: 1834.

19. Callet, Francois. Table des Logarithmes, V.II. Paris: 1795.

20. Chapman, William C. Vaccination as a Preventive of Small Pox. Toledo, Ohio: 1876.

21. Hertz, Heinrich. Miscellaneous Papers. London: 1896.

22. Warner, Joseph. Cases in Surgery. London: 1760.

23. (Hope, William.) The Sewage of the Metropolis. London: 1865.

24. Scherer, Alexander Nicolaus. Theophrastus Paracelsus. St. Petersburg: 1821.

25. Oliver, William. A Practical Essay. . . . Bath: 1753.

26. Tagault, Jean. Commentariorum de Purgantibus Medicamentis. Paris: 1537.

27. Störck, Anton. Libellus. Vienna: 1760. 
28. Lemnius, Levinus. Occulta Naturae Miracula Wunderbarliche. . . . Leipzig: 1588.

29. Valentin, Louis. Notice biographique sur le Docteur Jenner. (Montpellier: 1805.)

30. Pierce, Ray Vaughan. The People's Common Sense Medical Advisor. . . . Buffalo, N.Y.: 1895.

31. Talani, Vincente, pub. (Raccosta di Tutte le Vedute Rappresentanti l'Eruxione del Monte Vesuvio. . . .) Naples: 18??

32. Blackmore, Richard. Dissertations on a Dropsy. . . . London:1727.

33. Patin, Charles. De Aortae Polypo. . . . Brescia: 1731.

34. Pallas, August Friedrich. Chirurgie. . . . Berlin: 1776.

35. Hohenthal, Peter Freiherr von. Oeconomische Nachrichten, V.II. Leipzig: 1751.

36. Kloekhoff, Cornelis Albertus. Opusculum Medica Omnia. Jena: 1772.

37. MacDonald, George. Paul Faber, Surgeon. London: 1878.

38. Blagrave, Joseph. Blagrave's Supplement. . . . London: 1674.

39. Die Klosterküche von Wörishofen. Brixen: 1893.

40. Rostinio, Pietro. Compendio di Tutta la Cirurgia. Venice: 1677.

41. Bolmar, Antoine. A Collection of Colloquial Phrases. Philadelphia: 1834.

42. Osborne, E. C. Map of the London and Birmingham Railway. Birmingham: 1838.

43. Charleton, Walter. Exercitationes de Oeconomia Animali. Amsterdam: 1659.

\section{APPENDIX B: PRIORITY RANKINGS}

Volume

1: $26,8,10,9,36,33$

2: $7,1,27,5,1,15$

3: $7,10,15,39,21,21$

4: $6,42,30,41,43,40$

5: $12,7,22,1,4,10$

6: $1,20,26,37,32,33$

7: $5,7,9,5,13,6$

8: $15,18,4,5,2,2$

9: $12,4,10,2,8,7$

10: $15,13,6,10,6,10$

11: $19,10,24,22,18,19$

12: $11,4,30,3,3,3$

13: $30,20,35,22,32,36$

14: $17,16,11,35,38,3$

15: $17,4,30,22,41,25$

16: $22,31,15,3,4,8$

17: $22,4,30,18,21,12$

18: $3,7,3,13,3,1$

19: $37,41,35,41,40,33$

20: $34,31,42,35,41,43$

21: $7,23,28,32,10,29$

22: $26,31,43,27,26,15$
23: $30,42,38,13,36,26$

24: $33,39,34,37,38,21$

25: $40,40,28,27,18,13$

26: $19,3,13,13,26,3$

27: $22,31,19,10,21,23$

28: $22,1,2,18,10,18$

29: $40,37,40,39,29,41$

30: $34,31,37,18,32,15$

31: $19,13,13,13,13,8$

32: $26,23,30,13,26,32$

33: $26,20,30,10,21,25$

34: $1,31,6,27,13,25$

35: $4,2,5,27,13,25$

36: $7,23,15,32,18,14$

37: $12,38,26,27,21,41$

38: $37,16,11,22,13,24$

39: $42,13,40,43,30,36$

40: $34,29,25,5,17,29$

41: $43,27,23,32,32,25$

42: $37,29,38,18,30,25$

43: $30,18,19,22,10,29$

Note: In case of ties, all volumes receiving the same total value score were ranked equally. For example, in case of a three-way tie for 12 th place, all three volumes would be ranked 12; the volume with the next highest total value score would be ranked 15 . 